\title{
Polyethylene Nanodielectrics: The Influence of Nanoclays on Structure Formation and Dielectric Breakdown
}

\author{
Alun S. Vaughan Non-member (Southampton University, asv@ecs.soton.ac.uk) \\ Steven G. Swingler Non-member (Southampton University, sgs@ecs.soton.ac.uk) \\ Yudong Zhang Non-member (Southampton University, yz@ecs.soton.ac.uk)
}

Keywords : nanocomposite, montmorillonite, polyethylene, dielectric breakdown, crystallization, morphology

Polymeric composites containing nanometric fillers have attracted considerable interest because of the attractive properties that such materials can display. In the area of nanodielectrics, many workers have stressed the significance of the interfaces that exist between such fillers and the host polymer as being critical in influencing properties. Indeed, Tanaka ${ }^{(1)}$ proposed a concentric shell model in which interactions can be thought of as occurring at a range of dimensional levels; Nelson and Fothergill ${ }^{(2)}$ considered nanodielectrics in terms of an interaction zone. In this work, we set out to prepare a range of nanocomposites based on polyethylene (PE) and montmorillonite nanoclay (MMT), to examine the effect of MMT dispersion on properties and structure formation and, thereby, to explore both short-range molecular effects and the extent of the polymer/nanoclay interaction zone.

Figure 1 compares AC ramp breakdown results obtained from 3 materials at a ramp rate of $50 \mathrm{~V} \mathrm{~s}^{-1}$. Where dispersion of the MMT is poor (C Quenched), the breakdown strength is greatly reduced compared with a comparable system containing well-dispersed nanoclay (E Quenched). This is in line with behaviour reported for nano- and microcomposites ${ }^{(2)}$, suggesting that it is attributable to aggregation of the MMT in C. However, attempts to improve the breakdown strength of $\mathrm{E}$ by controlled crystallization were unsuccessful; systems prepared by rapid quenching from the melt or by prolonged isothermal crystallization both behaved in an equivalent manner. This is in contrast to the same polymer, but without MMT (B $117{ }^{\circ} \mathrm{C}$ ), where controlled crystallization can lead to improved properties, as reported elsewhere ${ }^{(3)}$. Thus, when quenched, equivalent polyethylene materials with and without MMT exhibit similar breakdown behaviour, provided the MMT is well dispersed. However, in the absence of MMT, isothermal crystallization can result in improved performance whereas, when MMT is present, this appears not to occur.

To explore the origin of the above effects, the influence of

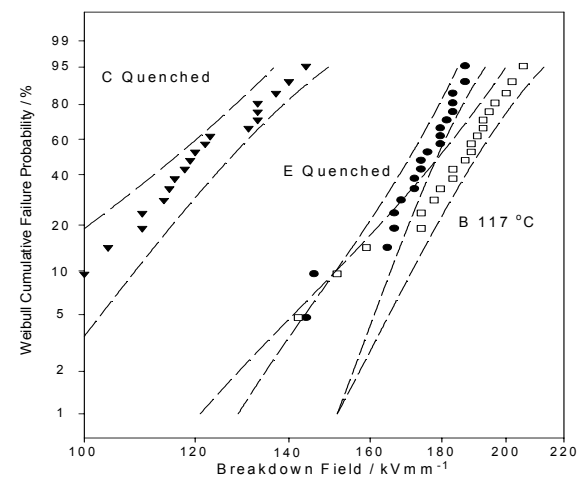

Fig. 1. Breakdown data showing the effect of MMT dispersion and controlled crystallization

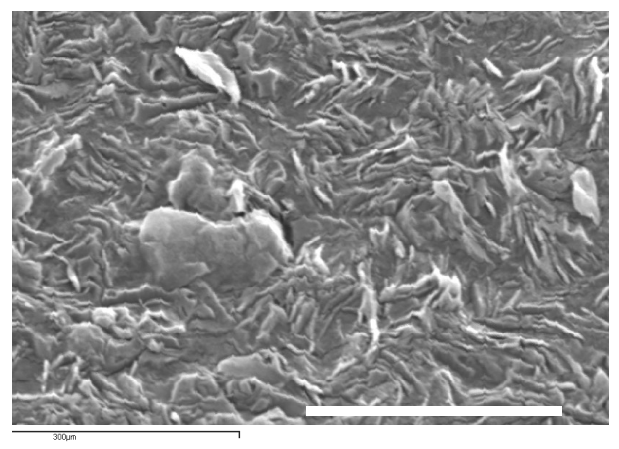

Fig. 2. SEM micrograph showing the morphology of material E after crystallization at $117^{\circ} \mathrm{C}$

MMT on structural evolution in PE was examined. In the scanning electron microscope (SEM), all the materials where MMT was absent or poorly dispersed were found to exhibit spherulitic morphologies. In contrast, Fig. 2 shows a sample of Material E, which contains $5 \%$ by weight MMT, following crystallization at $117{ }^{\circ} \mathrm{C}$. An MMT aggregate $\sim 1 \mu \mathrm{m}$ in size can be seen near the centre of this image but, elsewhere, it is not possible to distinguish MMT platelets from polymer lamellae. Although the material is highly nucleated, the lamellar texture also appears highly disrupted. Thus, in the absence of MMT or when the MMT is poorly dispersed, crystallization of the polymer leads to conventional morphologies, whereas well-dispersed MMT appears to promote nucleation but, subsequently, to disrupt the processes by which ordered structures form. This interpretation of fig. 2 is supported by quantitative studies of crystallization kinetics and the thermodynamics of crystallization. MMT increases the crystallization rate constant by some two orders of magnitude but simultaneously reduces the polymer's ability to crystallize isothermally by up to $50 \%$.

In conclusion, in the polyethylene systems studied here, there is clear evidence of both short-range interactions between the polymer and the nanofiller and a far more extensive interaction zone. Indeed, from a structural perspective, the interaction zone extends throughout the material. This, consequently, has a marked effect on properties; here, controlled crystallization appears ineffective in improving breakdown strength, because the MMT disrupts the formation of the required ordered morphology.

\section{References}

(1) T. Tanaka : IEEE Trans. Dielect. Elect. Insul., Vol.12, p.914 (2005)

(2) J. K. Nelson and J. C. Fothergill : Nanotechnology, Vol.15, p.586 (2004)

(3) I. L. Hosier, A. S. Vaughan, and S. G. Swingler : J. Mater. Sci., Vol.32, p.4523 (1997) 


\title{
Polyethylene Nanodielectrics: The Influence of Nanoclays on Structure Formation and Dielectric Breakdown
}

\author{
Alun S. Vaughan* Non-member \\ Steven G. Swingler* Non-member \\ Yudong Zhang* Non-member
}

\begin{abstract}
A range of nanocomposites containing polyethylene and montmorillonite (MMT) clay was prepared using different procedures, such that the extent of MMT dispersion varied. The interactions that occur were then studied, together with the effect of MMT dispersion on structure and short-term dielectric breakdown. When the MMT is poorly dispersed, the AC ramp breakdown strength is reduced. When the MMT is well dispersed, quenched samples with and without MMT appear to behave in an equivalent manner. However, while isothermal crystallization at $117{ }^{\circ} \mathrm{C}$ results in a significant increase in performance in the absence of MMT, no equivalent change was seen when the MMT was present. The crystallization behaviour of the polyethylene indicates that while well-dispersed MMT serves to enhance nucleation, it can also serve to inhibit crystallization. These results suggest that short-range thermodynamic interactions occur between the clay platelets and the polymer during the initial crystallization phase. The interaction zone can, however, be thought to extent throughout the material.
\end{abstract}

Keywords : polyethylene, nanocomposites, dielectric breakdown, crystallization, interactions

\section{Introduction}

Composites containing nanometric fillers have attracted considerable interest, because of their attractive properties. In dielectrics, the effect of nanometric fillers on dielectric constant, dielectric loss, space charge, conduction and breakdown have all been considered ${ }^{(1)-(5)}$. Although many different nanocomposites have been prepared ${ }^{(6)}$, systems including layered silicates such as montmorillonite (MMT) have attracted particular attention ${ }^{(7)}$. MMT is typically supplied as micron sized particles but, by suitable processing, the weak interlayer forces can be exploited to give high dispersions. In the case of complete exfoliation, the resultant material would contain an assembly of clay sheets $\sim 500 \mathrm{~nm}$ in lateral extent and a nanometre or so in thickness ${ }^{(8)}$.

The importance of polyethylene (PE) as an insulation material is increasing as polymers replace traditional paper/oil systems. Although certain aspects of the electrical properties of PE-based nanocomposites have been reported ${ }^{(2)(3)(9)}$, we are not aware of any previous studies of high field effects in polyethylene/MMT systems. Consequently, this study was undertaken to investigate the effect of an MMT clay on properties and structural evolution in a model polyethylene. Since the importance of interfaces in nanodielelectrics is well recognized ${ }^{(3)(10)-(12)}$, a principal objective concerned the interactions that occur between the polymer and the nanofiller. Following the pioneering ideas of Lewis ${ }^{(10)}$ Tanaka $^{(13)}$ has proposed a concentric shell model in which interactions can be thought of as occurring at a range of dimensional levels. Fleming et $a l^{(9)}$ suggested that the thickness of an interface layer should be taken as "the distance over which a given physical property changes from being characteristic of the particle to being characteristic of the host"; a typical value of $10 \mathrm{~nm}$ is suggested. Nelson and Fothergill ${ }^{(14)}$ have considered nanodielectrics in terms

* ECS, University of Southampton Highfield, Southampton SO17 1BJ, UK of local layers of immobilized polymer and, more generally, in terms of an interaction zone, where the presence of the nanofiller serves to modify the polymer's behaviour. In polyethylene, there is good reason to imagine that interaction zones could be extensive, since the dimensional scales involved in a well-dispersed MMT system are comparable to those exhibited by polyethylene lamellae, which are typically $10-20 \mathrm{~nm}$ in thickness and some microns in lateral extent ${ }^{(15)}$. Also, where polyethylene interacts strongly with an interface, a "memory" of this can be preserved in the microstructure for many microns ${ }^{(16)}$. In order to study both local interactions and broader interaction zones we set out to:

(1) Prepare materials with different degrees of MMT dispersion.

(2) Examine the effect of MMT dispersion on the crystallization kinetics of the host polyethylene matrix, in particular, to seek evidence of local interactions between the polymer and clay in terms of nucleation characteristics.

(3) To explore the effect of the MMT on the way in which the lamellar texture develops and, therefore, define the extent of the clay/polymer interaction zone.

(4) Conduct a preliminary study of the influence of the above on short-term AC dielectric breakdown behaviour.

\section{Experimental}

2.1 Materials The polymers used in this study were the linear, high density, polyethylene (LPE) Rigidex 160-25 (BP) and the branched, low density polyethylene (BPE) LD100BW (Exxon). Two MMT systems were examined, the octadecyl ammonium-modified montmorillonite I30P (Nanocor) ${ }^{(17)}$ and the polyethylene/MMT master batch (MB) C30PE (Nanocor); C30PE contains approximately 50\% MMT and 50\% polyethylene. Five specimen formulations, designated $\mathrm{A}$ to $\mathrm{E}$ were prepared using either solution blending in xylene, or melt mixing in a Randcastle RCP-0375 microtruder that incorporates a recirculating 
Table 1. Processing methods and composition, in parts by weight, of the materials considered here

\begin{tabular}{|c|c|c|c|c|c|}
\hline Material & LPE / Parts & BPE / Parts & Clay / Parts & Processing & Comments \\
\hline A & 10 & 90 & 0 & Solution & Reference \\
\hline B & 10 & 90 & 0 & Extruded & Effect of melt shear only \\
\hline C & 10 & 90 & 5 MMT I30P & Solution & Minimum dispersion \\
\hline D & 10 & 90 & 5 MMT I30P & Extruded & Intermediate dispersion \\
\hline E & 10 & 90 & 10 MB C30PE & Extruded & Maximum dispersion \\
\hline
\end{tabular}

mixing section to promote dispersion - see Table 1. The intention was to produce a range of systems with equivalent polymeric compositions, three of which would contain equivalent quantities of MMT. For Materials A to D, all contain 10 parts LPE and 90 parts BPE; Materials $\mathrm{C}$ and D contain an additional 5 parts MMT (i.e. $\sim 4.8$ weight percent). In contrast, the effective composition of Material E is more difficult to ascertain; $50 \%$ of the master batch is MMT, which equates to $\sim 4.5 \%$ by weight of the final system. In view of the uncertainties inherent in the blending process, all of our materials therefore contain equivalent amounts of MMT. The polymeric component of the master batch appears, from its thermal characteristics, to be a linear low density polyethylene (LLDPE). Such polymers exhibit crystallinities that resemble BPE but, typically, contain some higher melting fractions. LLDPE therefore has much in common with LPE/BPE blends and the isothermally crystallizable fraction in Material E should, consequently, be similar to that in our other systems.

2.2 Characterization Thermal analysis was carried out using a Perkin-Elmer DSC 7 differential scanning calorimeter (DSC), after calibration with sapphire and high purity indium. The crystallization and subsequent melting behaviour of samples of the order of $5 \mathrm{mg}$ in mass were investigated within the range $110^{\circ} \mathrm{C}$ to $123{ }^{\circ} \mathrm{C}$ and all data acquisition and analysis were performed using the Perkin Elmer Pyris software package.

The morphologies present within a range of samples were examined by scanning electron microscopy (SEM), following a two-stage etching procedure ${ }^{(18)}$. Internal surfaces were first exposed using an RMC CR21/MT7 cryo-ultramicrotome; this resulted in damage to the glass knives which, in turn, introduced unacceptable deformation into the sample surface. Each sample was first etched for $16 \mathrm{hr}$, in a reagent containing $1 \% \mathrm{w} / \mathrm{v}$ potassium permanganate in a mixture of 2 parts sulphuric acid to 1 part orthophosphoric acid, to "polish" the sample chemically. Then, samples were exposed to a $1 \% \mathrm{w} / \mathrm{v}$ solution of potassium permanganate in a mix of 5 parts concentrated sulphuric acid, 2 parts orthophosphoric acid and 1 part water. After $2 \mathrm{hr}$, the samples were recovered and sputter coated with gold.

2.3 Electrical Testing Thin film samples, $53 \pm 3 \mu \mathrm{m}$ in thickness, were prepared using a Graseby Specac press equipped with a thin film maker. After the thickness of each had been determined, it was immersed in silicone oil between vertically opposing $6.3 \mathrm{~mm}$ diameter ball bearing electrodes; a $50 \mathrm{~g}$ load was applied to the upper electrode and the lower electrode was connected to earth. A high-tension AC supply was then connected to the upper electrode and the applied voltage increased at a ramp rate of $50 \mathrm{~V} \mathrm{~s}^{-1}$ until the sample failed; twenty identical tests were performed on each material type. This ramp testing procedure is based upon the general considerations laid down in ASTM D149 $87^{(19) \sim(21)}$. The resulting breakdown data were analyzed assuming two parameter Weibull statistics ${ }^{(21)(22)}$, from which, values of the location parameter, $E_{o}$, and shape parameter, $b$, were estimated,

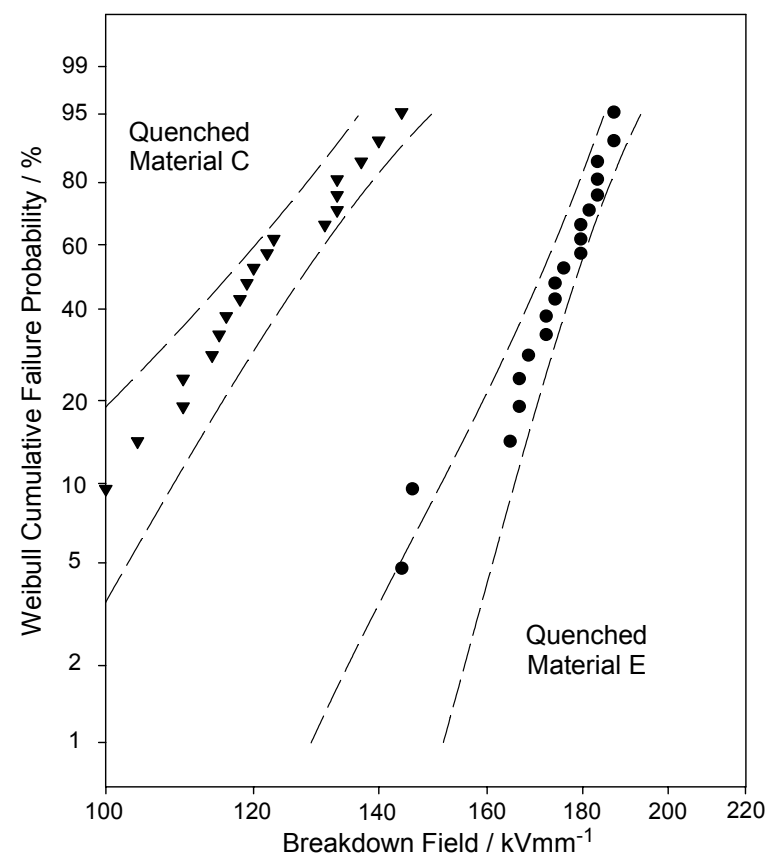

Fig. 1. Weibull plots comparing the breakdown characteristics of quenched samples of Material C and Material E

together with associated $90 \%$ confidence limits.

\section{Results}

3.1 Dielectric Breakdown

Figure 1 compares breakdown results obtained from Material $\mathrm{C}$ and Material $\mathrm{E}$ and shows the effect of MMT dispersion. Where the MMT has been poorly dispersed, in Material $\mathrm{C}$, the ramp breakdown strength is greatly reduced compared with the master batch system, Material E. This general behaviour is in line with that previously reported in systems based upon titania and an epoxy $\operatorname{resin}^{(14)}$, a copper phthalocyanine oligomer and a fluorinated copolymer ${ }^{(1)}$ and silica and polyethylene ${ }^{(3)}$. Conversely, Hong et $a l^{(2)}$ report that in their zinc oxide/polyethylene systems, micro- and nanocomposites behave similarly.

Figure 2 examines the effect of controlled crystallization on ramp breakdown in Material E. From this, it is evident that crystallization to completion at $117^{\circ} \mathrm{C}$ has no significant effect in this system. In contrast, from Fig. 3, in the same polymer blend produced using the same manufacturing process but without MMT, crystallization at $117{ }^{\circ} \mathrm{C}$ increases the breakdown strength relative to the same material when quenched. However, although the two data sets shown in Fig. 3 are clearly displaced from one another, the confidence limits do overlap at extreme values. This is primarily a result of the rather low $b$ value of 11.9 obtained from the quenched material, compared with $b=15.4$ for the isothermal equivalent. Nevertheless, it is important to ask the question: is this 


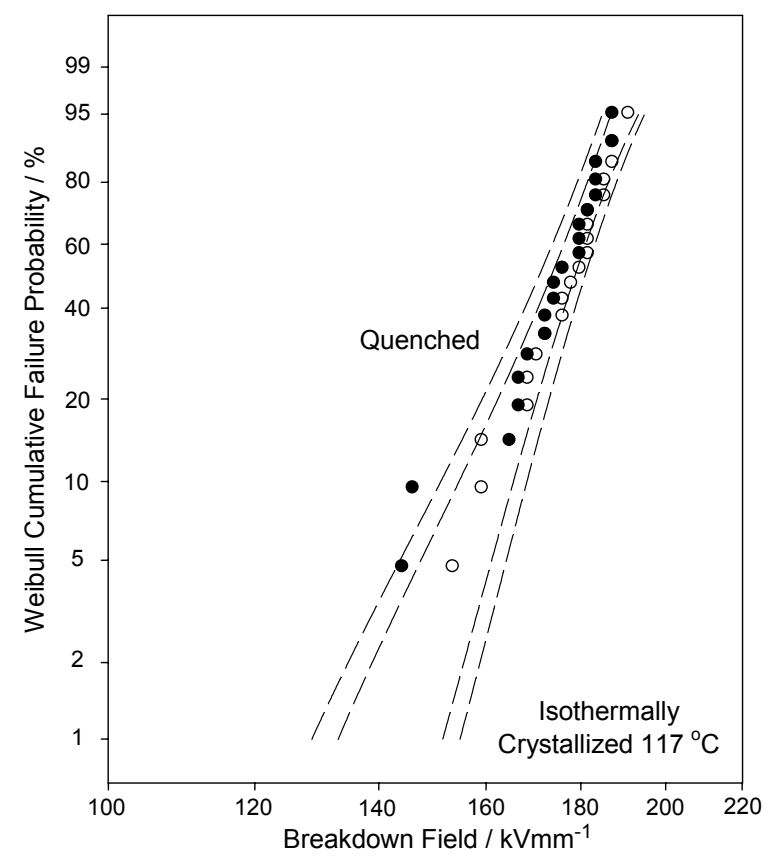

Fig. 2. SEM micrograph showing the morphology of Material E after crystallization at $117^{\circ} \mathrm{C}$; Scale bar : $5 \mu \mathrm{m}$

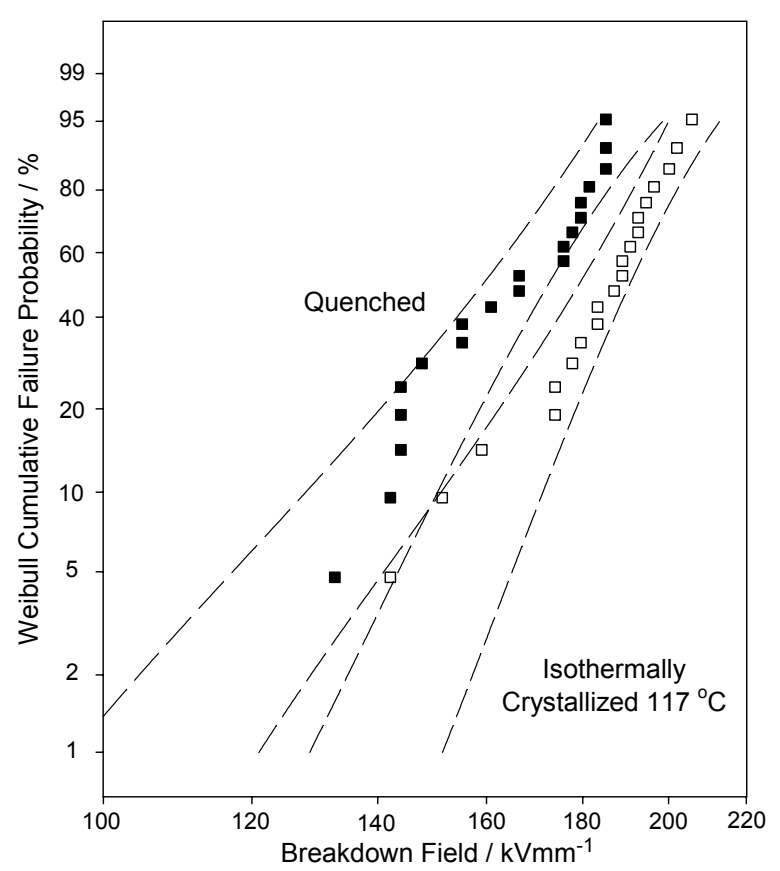

Fig. 3. Weibull plots showing the effect of crystallization conditions on the breakdown characteristics of Material B, without nanoclay

apparent effect real ? In isolation, we do not believe that the difference seen in Fig. 3 is convincing proof of the beneficial effect of isothermal crystallization. However, we have previously examined the effect of crystallization conditions and molecular composition on ramp breakdown in polyethylene blends in considerable detail and have shown that, for materials such as those used here, controlled crystallization at temperatures close to $115{ }^{\circ} \mathrm{C}$ does indeed result in an increase in breakdown strength $^{(23)-(25)}$. Also, Material A shows comparable behaviour ${ }^{(26)}$.

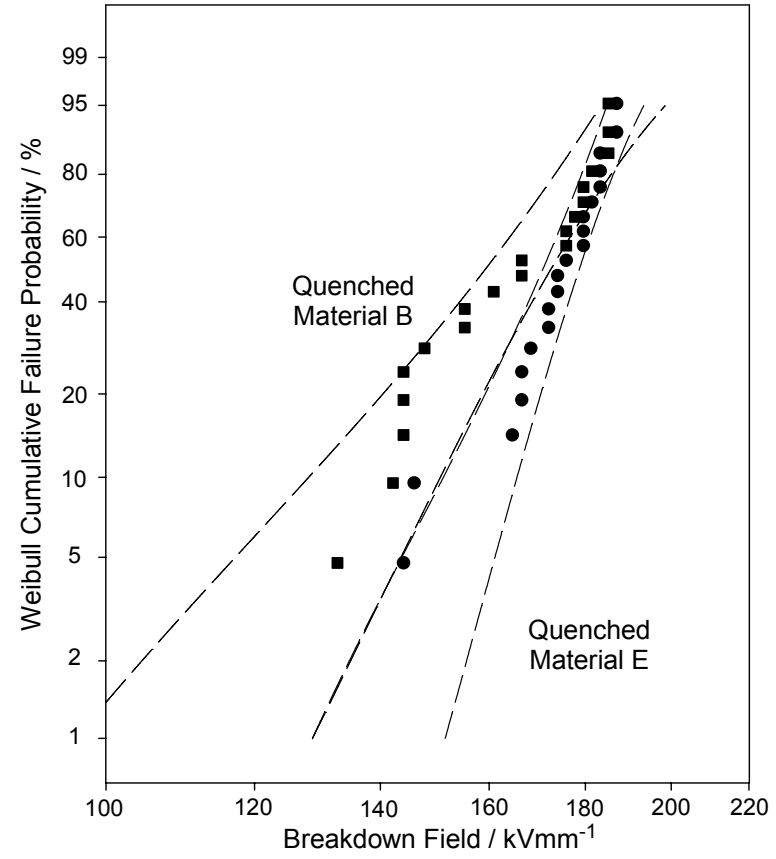

Fig. 4. Weibull plots comparing the breakdown behaviour of quenched samples of Materials B and E

Finally, it is worth comparing quenched samples of Materials B and E; Fig. 4 shows Weibull plots of data obtained from these. Above a cumulative failure probability of $40 \%$, the two systems behave identically; below $10 \%$, they are also comparable. Consequently, the confidence limits overlap over the complete range, even though the data corresponding to intermediate values differs between the two systems. Again, we attribute this to the high scatter present in the data obtained from Material B ( $b=$ 11.9) compared with that from Material E $(b=21.4)$.

To summarize: when quenched, equivalent polyethylene materials with and without MMT exhibit statistically equivalent breakdown behaviour, provided the MMT is well dispersed. In the absence of MMT, isothermal crystallization at moderate temperatures results in an improvement in performance whereas, when MMT is present, this does not seem to occur. Similar conclusions have been drawn elsewhere, based upon different data sets $^{(27)}$, and therefore, these effects appear reproducible.

3.2 Material Microstructure Figure 5 shows exfoliated MMT, together with larger aggregates, as revealed by transmission electron microscopy. While such micrographs provide a direct means of imaging the local MMT structure, they do not reveal the relationships between the MMT and the surrounding polymer microstructure. Specifically, does the MMT modify the local polymer morphology and, if so, over what distance does the memory of these interactions persist?

To address such questions, an alternative approach was explored. Figure 6 shows an SEM image of an etched surface of Material A crystallized at $117{ }^{\circ} \mathrm{C}$, from which it is evident that this procedure results in the growth of banded spherulites ${ }^{(15)}$. These are composed of a framework of isothermal LPE lamellae separated from one another by quenched BPE, as reported elsewhere ${ }^{(23)(24)}$. Figure 7 shows a similar micrograph of Material C; that is, Material A plus 5 parts of MMT incorporated via a solution route. At moderate magnifications, spherulites can again be seen, although in this part of the specimen, these appear to be separated 


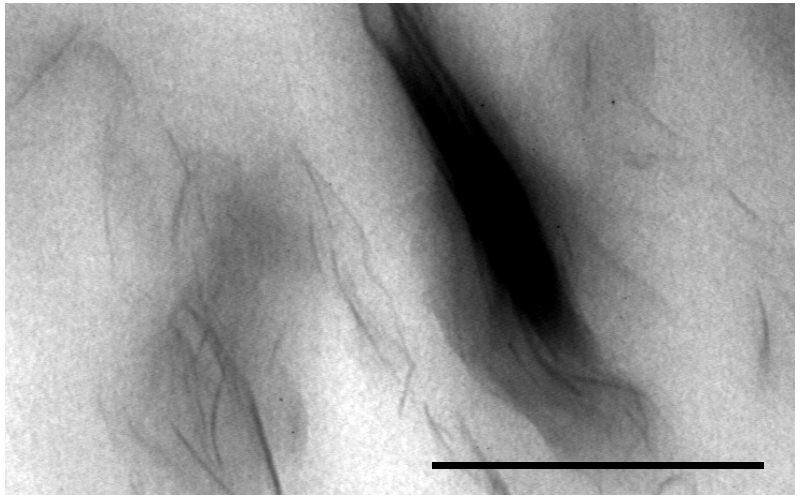

Fig. 5. Conventional bright field transmission electron micrograph of a polyethylene/MMT nanocomposite; Well separated MMT layers can be seen together with a much larger aggregate (dark area); Scale bar: $1 \mu \mathrm{m}$

from one another by distinct interspherulitic boundary regions. Where spherulites develop in close proximity to MMT (arrowed), there is no evidence of any interaction between the two components. As shown at a lower magnification in Fig. 8, it is apparent that with this processing route, extremely large clay aggregates exist within this material, which exceed the quoted size range for Nanocor $\mathrm{I}_{30} \mathrm{P}^{(17)}$. Nevertheless, Figs. 7 and 8 reveal three significant facts:

(1) The chosen solution processing route did indeed give rise to minimal dispersion of the MMT; X-ray data demonstrate that while this is an appropriate means of achieving intercalation in more polar ethylene-based copolymers, it does not occur here ${ }^{(27)}$.

(2) The similarity between the breakdown characteristics shown in Fig. 1 and those reported by Nelson and co-workers ${ }^{(3)(14)}$ is indeed a direct result of the aggregation state of the MMT in Material C. In terms of structure, Material $\mathrm{C}$ has more in common with a micro-composite and, hence, it exhibits similar behaviour.

(3) Even at low magnifications, the lamellar texture of Material $\mathrm{C}$ can be clearly differentiated from the MMT.

The situation is, however, very different in Material E; that is, the system in which we set out to maximize MMT dispersion. From Fig. 9, it is apparent that this material still contains extensive aggregates of MMT but, apparently, these are not sufficient to influence its ramp breakdown behaviour detrimentally. Figure 9 also suggests that the presence of the MMT in Material E has served to perturb morphological evolution in the surrounding polymer since, at low magnifications, there is no evidence of the spherulitic texture that can be seen elsewhere. Examination at higher magnifications confirms this. An MMT aggregate, about $\sim 1$ $\mu \mathrm{m}$ in size, can be seen at the centre of Fig. 10 but, elsewhere, it is not possible clearly to distinguish MMT platelets from polymer lamellae. Indeed, the whole microstructure appears highly disrupted, in sharp contrast to the typical polyethylene lamellar textures seen in Figs. 6 to 8 .

To summarize: in the absence of MMT, or where the MMT is poorly dispersed, crystallization of the matrix polymer occurs as seen elsewhere to give conventional lamellar morphologies. Conversely, it would appear that the presence of well dispersed MMT serves to disrupt completely the processes by which isothermal crystallization gives rise to ordered lamellar textures.

3.3 Crystallization Behaviour The kinetics of polymer crystallization were analysed using the Avrami equation ${ }^{(28)-(30)}$ :

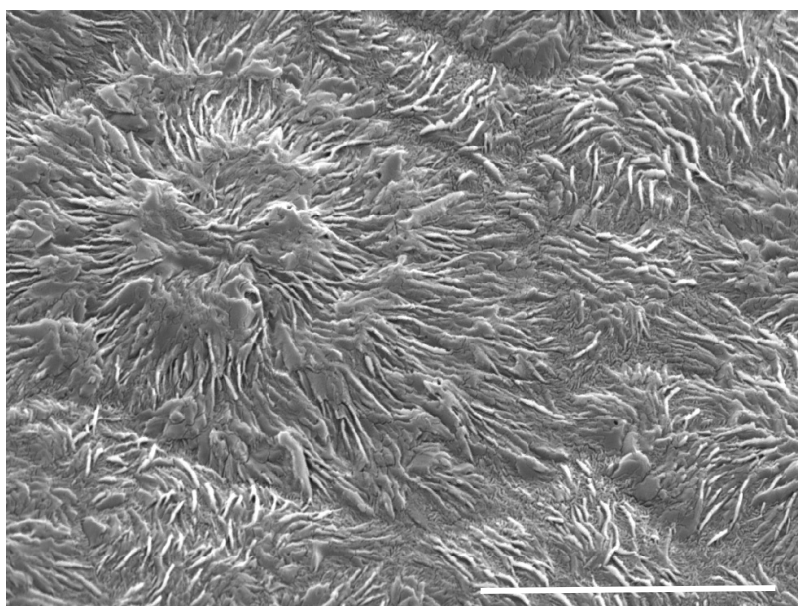

Fig. 6. SEM micrograph showing the normal spherulitic structure of polyethylene that develops in the absence of MMT (Material A); Scale bar: $10 \mu \mathrm{m}$

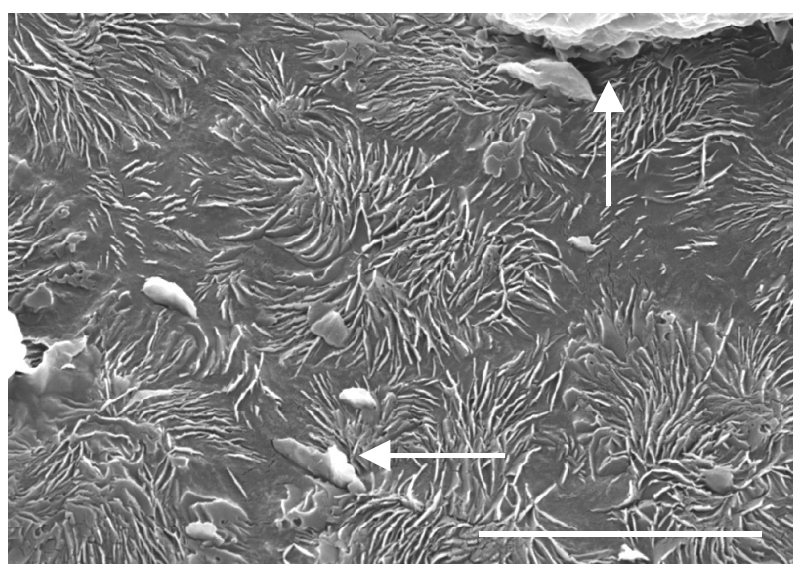

Fig. 7. SEM micrograph showing the structure of Material C; In addition to the spherulitic lamellar texture of the polymer, aggregates of MMT can also be seen as bright inclusions; Scale bar: $10 \mu \mathrm{m}$

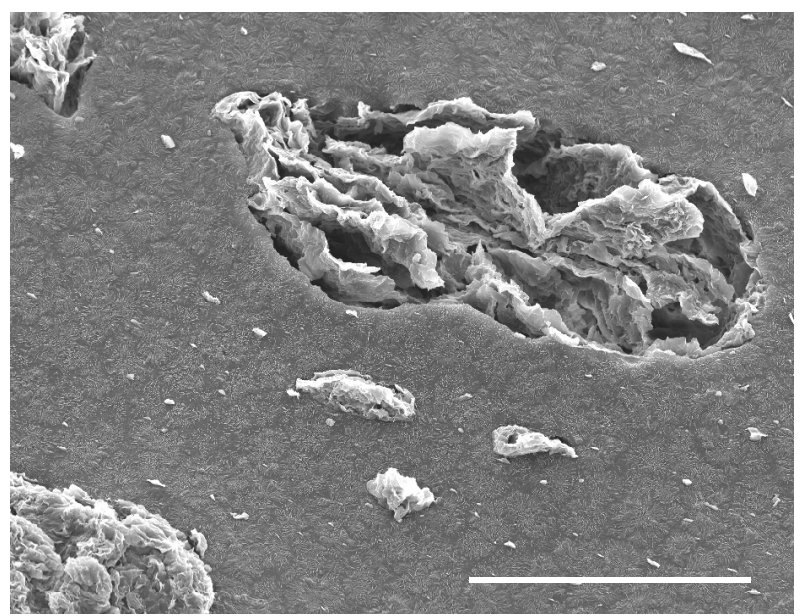

Fig. 8. Low magnification SEM image of Material C; Large aggregates of MMT can be see together with the background spherulitic texture; Scale bar: $80 \mu \mathrm{m}$ 


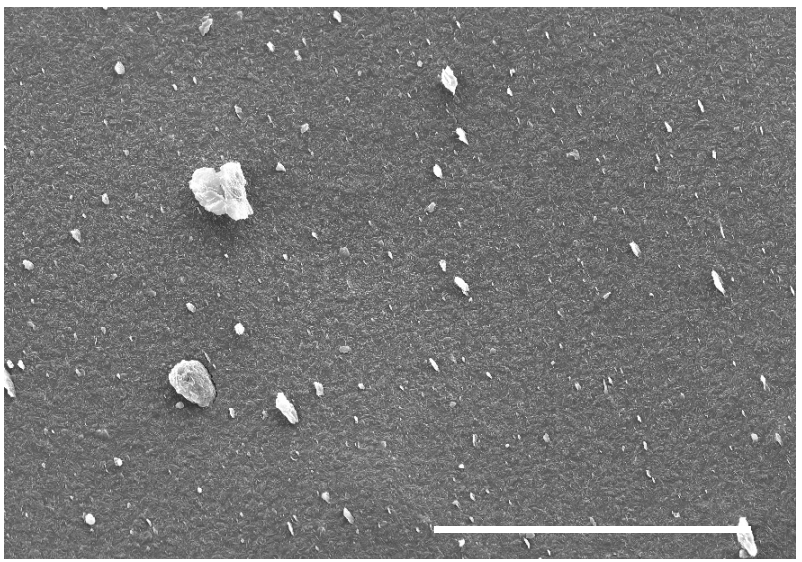

Fig. 9. Low magnification SEM image of Material E; Sizable aggregates of MMT can still be readily seen as bright inclusions; the structure of the matrix polymer is, however, unclear; Scale bar: $80 \mu \mathrm{m}$

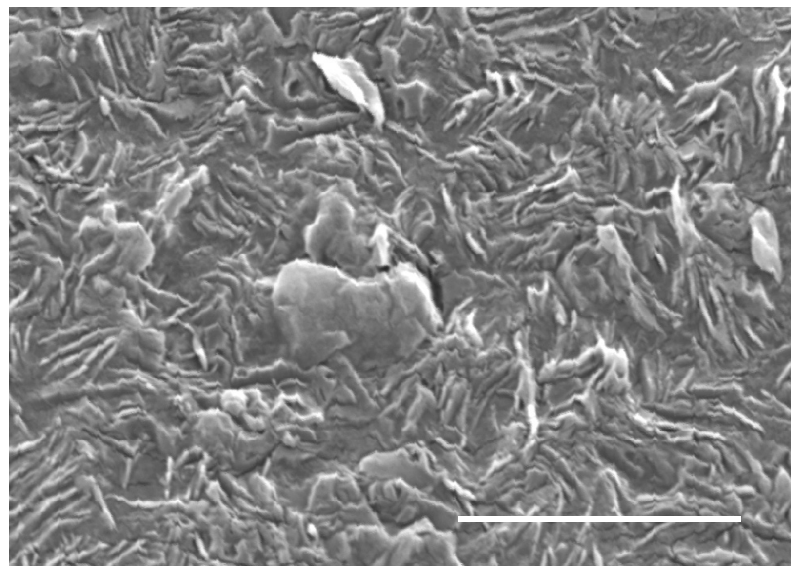

Fig. 10. High magnification SEM micrograph of Material E; A $\sim 1 \mu \mathrm{m}$ aggregates of MMT can be seen at the centre of the images; Elsewhere the MMT and the polymer lamellae cannot be differentiated and the overall structure appears highly perturbed by the well-dispersed MMT; Scale bar: $5 \mu \mathrm{m}$

$$
1-\frac{V_{c}}{V_{\mathrm{inf}}}=\exp \left(-K_{\mathrm{exp}} t_{c}^{n}\right)
$$

In this, $V_{c}$ is the volume fraction of crystallinity at time $t_{c}, V_{\text {inf }}$ is the maximum crystallinity attained, $K_{\exp }$ is the experimental rate constant and $n$ is the so-called Avrami exponent, which can be interpreted as a dimensionality ${ }^{(31)}$. However, it is generally assumed that non-integral values of $n$ are caused by factors such as secondary crystallization and mixed nucleation modes, rather than being a genuine reflection of non-three dimensional development. Under these circumstances, Kowalewski and Galeski $^{(32)}$ suggested that the effective 3-dimensional crystallization rate constant, $K_{3}$, can be determined from the experimentally measured $K_{\exp }$ using the relationship:-

$$
K_{3}=\frac{4}{3} \pi N G^{3} \cong\left(K_{\exp }\right)^{3 / n}
$$

where $N$ represents the number of nucleation sites per unit volume and $G$ is the growth rate of the crystallizing objects.

The value of this approach is that heterogeneous nucleation is

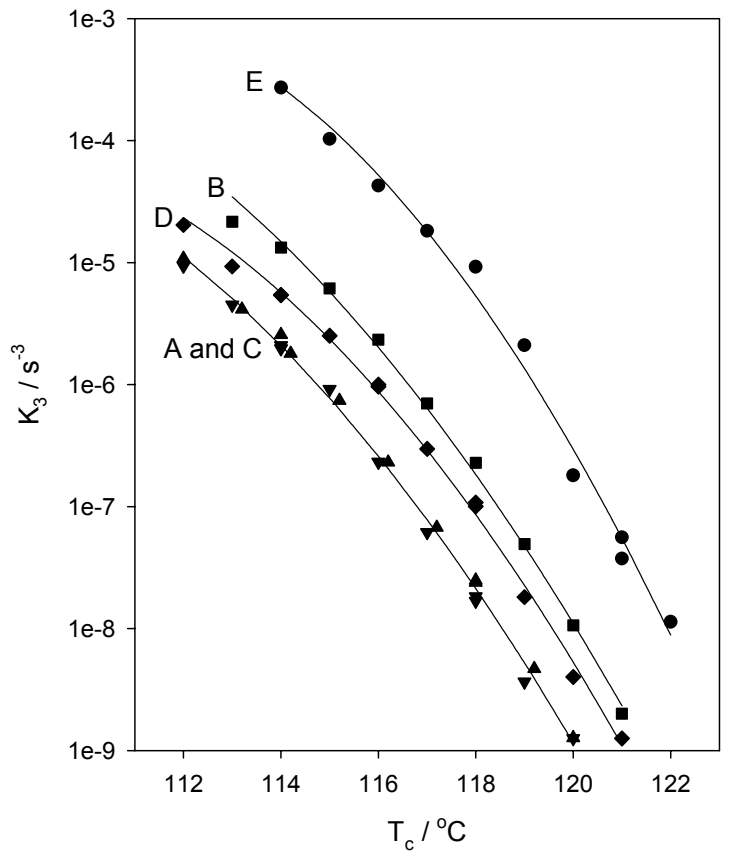

Fig. 11. Plots showing the effect of crystallization temperature on the Avrami K3 parameter for all 5 polyethylene/MMT systems

closely related to the local interactions that occur between the crystallizing polymer and the substrate - the difference energy parameter in the theory of Muchová and Lednický( ${ }^{(35)}$. In short, where the polymer and substrate interact strongly, one would expect nucleation to be enhanced whereas, where the polymer does not "see" the substrate, nucleation should occur as if it were not present. Consequently, here, $N$ will reflect the local molecular interactions that occur between the MMT and the polymer. However, to determine the absolute number of nuclei from Eq. (2), $G$ must be known. This is not a problem in the case of materials that do not contain MMT, since growth rates can then be measured directly. For systems containing MMT this is not possible and, therefore, we present our results here, not in terms of absolute nucleation densities but, rather, in terms of the crystallization rate constant $K_{3}$. This removes the need to assume that crystal growth occurs in the same way in all of our systems.

Figure 11 shows $K_{3}$ data derived from all 5 systems. From this, it is apparent that at any given temperature this parameter varies greatly, depending upon the composition of the material and its processing history. Materials $\mathrm{A}$ and $\mathrm{C}$ are indistinguishable and display the lowest values of $K_{3}$. The addition of the MMT by solution processing has therefore had a negligible effect on the crystallization kinetics of the host polymer, implying that there are negligible interactions between the polymer and micron-scale MMT inclusions. This conclusion is consistent with the microstructures shown in Figs. 7 and 8. Conversely, in Material E, where the MMT is well distributed, $K_{3}$ is enhanced by 2 to 3 orders of magnitude. Although, the melt shear associated with extrusion will have contributed to this ${ }^{(34)}$, the behaviour of Material E provides clear evidence of the nucleating effect of this MMT and therefore, evidence of local interactions; previous studies of polymer/MMT systems have led to conflicting conclusions concerning the effectiveness of MMT as a 
nucleant ${ }^{(17)(35)(36)}$. However, in comparison with other highly nucleated polymers, the degree of nucleation enhancement implied by Fig. 11 is not sufficient to explain the disordered structure shown in Fig. 10 $0^{(37)}$, implying that other processes must also be operating. Finally, the behaviour of Material D is intriguing. This material will have experienced a comparable shear history to that of Material B and therefore, the nucleation density in material D $\left(N_{D}\right)$ should be at least as high as the nucleation density in Material B $\left(N_{B}\right)$. Therefore, since MMT is an additional potential nucleant:

$$
N_{D} \geq N_{B}
$$

The observation that this is not mirrored in $K_{3}$ could suggests that the uncertainty in all the data obtained from Material D is such that they happen to lie between the results obtained from Materials $\mathrm{A}$ and $\mathrm{B}$. While this is hard to understand in terms of random errors, some systematic perturbation could manifest itself in this way. To eliminate this possibility, a reduced subset of data was acquired in a single session from all these samples, which served to reinforce the trends shown in Fig. 11. The alternative interpretation is that $K_{3}$ is being suppressed in Material $\mathrm{D}$, as a result of the MMT acting to reduced $G$, the rate of crystal growth.

\subsection{Thermodynamics of Crystallization and Melting}

Polymers such as polyethylene are semicrystalline materials composed of crystalline structures separated from one another by amorphous regions. The level of crystallinity present will depend upon the thermal history and molecular composition of the material. Figure 12 compares data derived from Materials B and E. In generating this figure, the enthalpies of crystallization and melting were determined as a function of crystallization temperature for each material and then converted into the percentage of the LPE present in each blend that was involved in each phase transition ${ }^{(38)}$. A detailed discussion of the various features of this figure is not warranted here; rather, we will

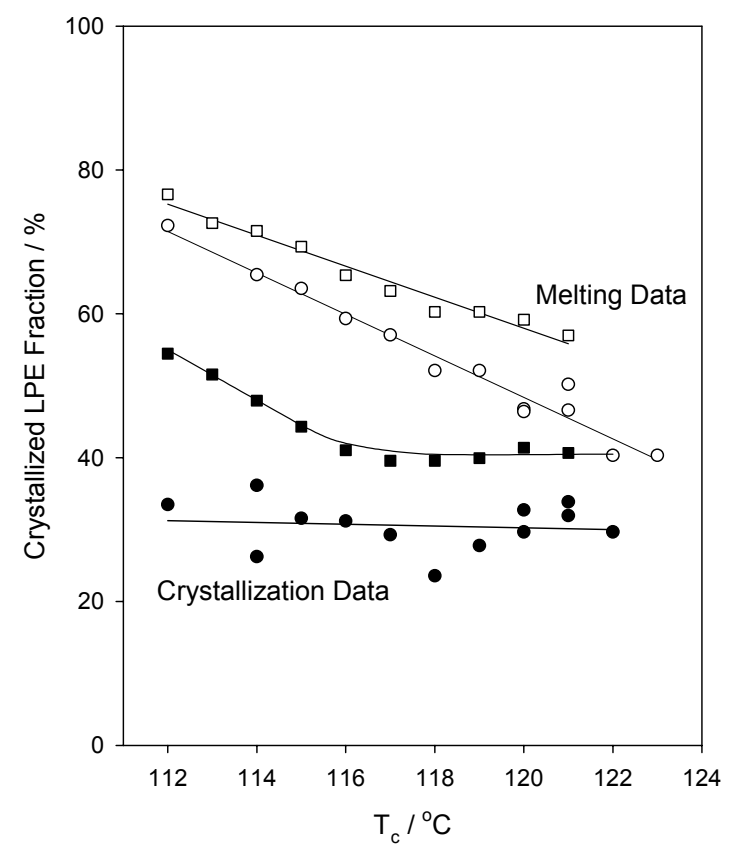

Fig. 12. Plots showing that MMT can serve to inhibit crystallization; Solid symbols: crystallization; Open symbols: melting. B $\square \square$ : E $\bigcirc$ concentrate on just those factors that relate to data presented in previous sections of this paper.

(1) In Material E, only some $30 \%$ of the available LPE was able to crystallize under isothermal conditions. This fraction is independent of the crystallization temperature.

(2) Conversely, in Material B, between 40 and $55 \%$ of the LPE was able to crystallize isothermally.

(3) Quenching and scanning in the DSC results in annealing effects that increase these crystallinity values but, on melting, Material E still contains fewer extensive, high melting LPE crystals than Material B.

(4) Figure 12 therefore contains strong quantitative evidence that, the presence of the MMT in Material E does indeed inhibit the formation of crystalline structures. The X-ray data of Lincoln et $a l^{(8)}$ led them to conclude that, in Nylon, MMT leads to the development of more disordered morphologies, while $\mathrm{Hu}$ and Lesser $^{(35)}$ have suggested that, in poly(trimethylene terephthalate) the presence of MMT serves to inhibit the transport of molecular segments to growing crystal interfaces and, by implication, suppresses crystal growth. Despite this, these workers reported an increase in the enthalpy of crystallization in the presence of MMT, albeit under non-isothermal conditions.

\section{Conclusions}

The data presented above were derived using a range of different approaches which, in concert, provide complementary views of the interactions that occur within MMT/polyethylene nanocomposites. Based upon these, we suggest that in our polyethylene/MMT systems, interactions do indeed occur at a range of length scales, as proposed by Tanaka ${ }^{(13)}$ and by Nelson and Fothergill ${ }^{(14)}$. Local interactions manifest themselves in modified nucleation behaviour of the polymer; well dispersed MMT results in the perturbation of crystal growth in the polymer, such that the interaction zone can be considered to extend through the material. Such a model of structural evolution would have a number of consequences:

(1) Crystal growth rates would be reduced, with a commensurate reduction in $K_{3}$ for a given nucleation density. Evidence for this is seen in the anomalously low values of $K_{3}$ for Material D in Fig. 11.

(2) The enthalpy of crystallization would be reduced, as is shown experimentally in Fig. 12.

(3) Structurally, the material would appear excessively disordered - the morphology shown in Fig. 10 cannot be ascribed solely to enhanced nucleation.

(4) The increase in breakdown strength that is seen to follow isothermal crystallization in the absence of MMT, has been related directly to an improvement in structural ordering. If this were prevented by the MMT, then isothermal crystallization would be expected to have little or no effect in well-dispersed MMT-based nanocomposites. - as seen in Fig. 2

In summary, we believe that the overall picture that emerges from the results presented above is a remarkably consistent one. The principal conclusion is that, interactions occur on a range of different levels. These occur locally, to influence nucleation, but, globally, serve to modify crystal growth such that the whole polymer matrix is affected. In this way, the interaction zone can be considered to extend throughout the material.

\section{Acknowledgements}

The authors wish to thank Dr Ian Hosier, Mr Christopher Green 
and Mr Gabriele Gherbaz for the contributions they have made to this study.

(Manuscript received Jan. 20, 2006; revised July 12, 2006)

\section{References}

(1) J. -W. Wang, Q. -D. Shen, C. -Z. Yang, and Q. -M. Zhang : "High dielectric constant composite of $\mathrm{P}(\mathrm{VDF}-\mathrm{TrFE})$ with grafted copper phthalocyanine oligomer", Macromolecules, Vol.37, pp.2294-2298 (2004)

(2) J. I. Hong, L. S. Schadler, R. W. Siegel, and E. Mårtensson : "Rescaled electrical properties of $\mathrm{ZnO} /$ low density polyethylene nanocomposites", Appl. Phys. Lets., Vol.82, pp.1956-1958 (2003)

(3) M. Roy, J. K. Nelson, R. K. MacCrone, L. S. Schadler, C. W. Reed, R. Keefe, and W. Zenger : "Polymer nanocomposite dielectrics - the role of the interface", IEEE Trans. Dielect. Elect. Insul., Vol.12, pp.629-643 (2005)

(4) C. Li, A. Tang, Y. Zou, and X. Liu : "Preparation and dielectric properties of polyarylene ether nitriles/ $/ \mathrm{TiO}_{2}$ nanocomposite film", Mater. Lett., Vol.59, pp.59-63 (2005)

(5) J. -W. Wang, Q. -D. Shen, H. -M. Bao, C. -Z. Yang, and Q. -M. Zhang : "Microstructure and dielectric properties of $\mathrm{P}(\mathrm{VDF}-\mathrm{TrFE}-\mathrm{CFE})$ with partially grafted copper phthalocyanine oligomer", Macromolecules, Vol.38, pp.2247-2252 (2005)

(6) T. Tanaka, G. C. Montanari, and R. Mülhaupt : "Polymer nanocomposites as dielectrics and electrical insulation - perspectives for processing technologies, material characterization and future applications", IEEE Trans. Dielect. Elect. Insul., Vol.11, pp.763-784 (2004)

(7) S. S. Ray and M. Okamoto : "Polymer/layered silicate nanocomposites: a review from preparation to processing", Prog. Polym. Sci., Vol.28, pp.1539-1641 (2003)

(8) D. M. Lincoln, R. A. Vaia, and R. Krishnamoorti : "Isothermal crystallization of nylon-6/montmorillonite nanocomposites", Macromolecules, Vol.37, pp.4554-4561 (2004)

(9) R. J. Fleming, T. Pawlowski, A. Ammala, P. S. Casey, and K. A. Lawrence : "Electrical conductivity and space charge in LDPE containing $\mathrm{TiO}_{2}$ nanoparticles", IEEE Trans Dielect. Elec.t Insul., Vol.12, pp.745-753 (2005)

(10) T. J. Lewis : "Nanometric dielectrics", IEEE Trans. Dielect. Elect. Insul., Vol.1, pp.812-825 (1994)

(11) T. J. Lewis : "Interfaces and nanodielectrics are synonymous", Proc. ICSD, IEEE, pp.792-795, Piscataway (2004)

(12) T. J. Lewis : "Interfaces: nanometric dielectrics", J. Phys. D: Appl. Phys., Vol.38, pp.202-212 (2005)

(13) T. Tanaka : "Dielectric nanocomposites with insulating properties", IEEE Trans. Dielect. Elect. Insul., Vol.12, pp.914-928 (2005)

(14) J. K. Nelson and J. C. Fothergill : "Internal charge behaviour of nanocomposites", Nanotechnology, Vol.15, pp.586-595 (2004)

(15) D. C. Bassett : Principles of Polymer Morphology, Cambridge University Press, Cambridge (1981)

(16) M. I. A. el Maaty and D. C. Bassett : "On interfering nuclei and their novel kinetics during the crystallization of polyethylene from the melt", Polymer, Vol.42, pp.4965-4971 (2001)

(17) R. Nowacki, B. Monasse, E. Piorkowska, A. Galeski, and J. M. Haudin : "Spherulite nucleation in isotactic polypropylene based nanocomposites with montmorillonite under shear", Polymer, Vol.45, pp.4877-4892 (2004)

(18) R. H. Olley and D. C. Bassett : "An improved permanganic etchant for polyolefines", Polymer, Vol.23, pp.1707-1710 (1982)

(19) D. Fournier and L. Lamarre : "Interfacial breakdown phenomena between two EPDM surfaces", Proc. 6th DMMA, IEE, pp. 330-333, Manchester, London (1992)

(20) A. Gustafasson and U. W. Gedde : "Electrical degradation of polyethylene/polystyrene blends", Proc. Nordic Insul. Symp., pp.8.4:1-6, Vasteras (1992)

(21) L. A. Dissado and J. C. Fothergill : Electrical Degradation and Breakdown in Polymers, G. C. Stevens, Ed., Peter Peregrinus, London (1992)

(22) W. Weibull : "A statistical distribution function of wide applicability", $J$. Appl. Mechs., Vol.18, pp.293-297 (1951)

(23) I. L. Hosier, A. S. Vaughan, and S. G. Swingler : "Structure-property relationships in polyethylene blends: the effect of morphology on electrical breakdown strength", J. Mater. Sci., Vol.32, pp.4523-4531 (1997)

(24) I. L. Hosier, A. S. Vaughan, and S. G. Swingler : "On the effects of morphology and molecular composition on the electrical strength of polyethylene blends", J. Polym. Sci.: Polym. Phys. Ed., Vol.38, pp.2309-2322 (2000)

(25) I. L. Hosier, A. S. Vaughan, and S. G. Swingler : "The effects of measuring technique and sample preparation on the breakdown strength of polyethylene", IEEE Trans. Dielect. Elect. Insul., Vol.9, pp.353-361 (2003)

(26) A. S. Vaughan, C. D. Green, Y. Zhang, and G. Chen : "Nanocomposites for high voltage applications: effect of sample preparation on AC breakdown statistics”, Ann. Rep. CEIDP, IEEE, pp.732-735, Piscataway (2005)

(27) A. S. Vaughan, G. R. Mitchell, and Y. Zhang : unpublished work.

(28) M. Avrami : "Kinetics of phase change. I General theory", J. Chem. Phys., Vol.7, pp.1103-1112 (1939)

(29) M. Avrami : "Kinetics of phase change. II Transformation-time relations for random distribution of nuclei", J. Chem. Phys., Vol.8, pp.212-224 (1940)

(30) M. Avrami : "Granulation, phase change, and microstructure kinetics of phase change", J. Chem. Phys., Vol.9, pp.177-184 (1941)

(31) Z. L. Bo and Y. P. Shen : "Transformation kinetics of liquid-crystallines based on 1,4-phenylene 4-n-alkylbenzoate-4-allyloxybenzoate by DSC", Int. J. Chem. Kin., Vol.29, pp.317-321 (1997)

(32) T. Kowalewski and A. Galeski : "Influence of chalk and its surface-treatment on crystallization of filled polypropylene", J. Appl. Polym. Sci., Vol.32, pp.2919-2934 (1986)

(33) M. Muchová and F. Lednický : "Investigation of heterogeneous nucleation using the induction time of crystallization: 1. Theory of induction time", Polymer, Vol.37, pp.3031-3036 (1996)

(34) J. A. Pople, G. R. Mitchell, S. J. Sutton, A. S. Vaughan, and C. K. Chai : "The development of organized structures in polyethylene crystallized from a sheared melt, analyzed by WAXS and TEM", Polymer, Vol.40, pp.2769-2777 (1999)

(35) X. Hu and A. J. Lesser : "Non-isothermal crystallization of poly(trimethylene terephhthalate) PTT/clay nanocomposites", Macromol. Chem. Phys., Vol.205, pp.574-580 (2004)

(36) P. Maiti, P. H. Nam, M. Okamoto, N. Hasegawa, and A. Usuki: "Influence of crystallization on intercalation, morphology and mechanical properties of polypropylene/clay nanocomposites", Macromolecules, Vol.35, pp.2042-2049 (2002)

(37) A. S. Vaughan and I. L. Hosier : "The effect of dibenzylidene sorbitol on the crystallization behaviour of polyethylene", submitted to Polym. Commun.

(38) L. Mandelkern : "Crystallization and melting", in Comprehensive Polymer Science: Vol.2, Polymer Properties, C. Booth and C. Price Eds., pp.363-414, Pergamon Press, Oxford (1992)

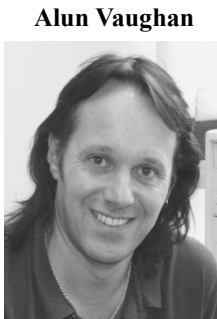

(Non-member) was born in Aberdare, UK, on July 24th 1959, received a Ph.D. in polymer physics from The University of Reading in 1984 and now holds the title of Reader in Polymeric Materials at the University of Southampton. He is an EPSRC College member and is Honorary Treasurer of The Dielectrics Group of the Institute of Physics. UK Institute of Physics, UK Institution of Electrical Engineers member.

Steve Swingler

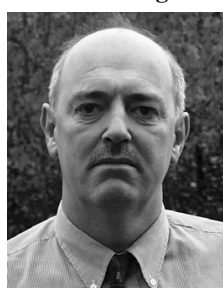

(Non-member) was born in Kettering, UK, on January 31st 1951 and received a Ph.D. in physics from the University of Lancaster. In 1976, he was appointed Pirelli Research Fellow at Southampton University, before moving to Leatherhead to join CERL and then the National Grid Company in 1989. In 2003, he returned to Southampton University as Professor in Transmission Asset Engineering. He is the UK Member of CIGRE Study Committee B1.

Yudong Zhang

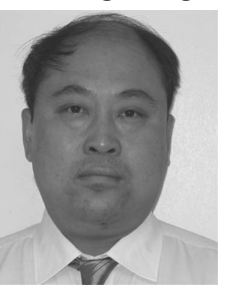

(Non-member) was born in Dalian City, China, on September 9th 1963 and was awarded a Ph.D. in Polymer Materials Engineering by Beijing University, China, in 1994. He has over fifteen years industrial and research experience in polymer science in China, the UK and the USA. In 1998, the State-Bureau of Petroleum and Chemical Industry of PR China awarded him the Science and Technology Progress Prize. 